\title{
Comparison of FACT Devices to Control Reactive Power in Long Distance High Voltage Transmission Line
}

\author{
Santosh \\ Grampurohit \\ Tushar \\ Pratik \\ Prof. Rozina \\ Gadhavi \\ Boksha \\ Surani \\ U.G. Scholar \\ U.G. Scholar \\ U.G. Scholar \\ Assistant \\ Professor
}

\begin{abstract}
Electrical Engineering Department, Vishwakarma Government Engineering College, Gandhinagar, Gujarat Pin- 382424, India
\end{abstract}

\begin{abstract}
In a long distance transmission line to control reactive power is a major issue. Here an attempt has been done by us, as undergraduate level by preparing a model of long distance transmission line. Firstly we have simulated an uncompensated line in a matlab/simulink environment and then by using different FACT devices he same line has been controlled for different loading condition.
\end{abstract}

\section{INTRODUCTION}

Modern power system is complex and it is essential to fulfil the demand with better power quality. Advanced technologies are nowadays being used for improving power system reliability, security and profitability and due to this power quality is improved.

Voltage stability, voltage security and power profile improvement are essential for power quality improvement. To achieve optimum performance of power system it is required to control reactive power flow in the network. Construction of new transmission lines and power stations increase the problem of system operation as well as the overall cost.

Regulatory limitation on the expansion of system network has resulted in reduction in stability margin thereby increasing the risk of voltage collapse.

Voltage collapse occurs in power system when system is faulted, heavily loaded and there is a sudden increase in the demand of reactive power. Voltage instability in power system occurs when the system is unable to meet the reactive power demand.

Reactive power imbalance occur when system is faulted, heavily loaded and voltage fluctuation is there. Reactive power balance can be regained by connecting a device with the transmission line which can inject or absorb reactive power based on system requirement.

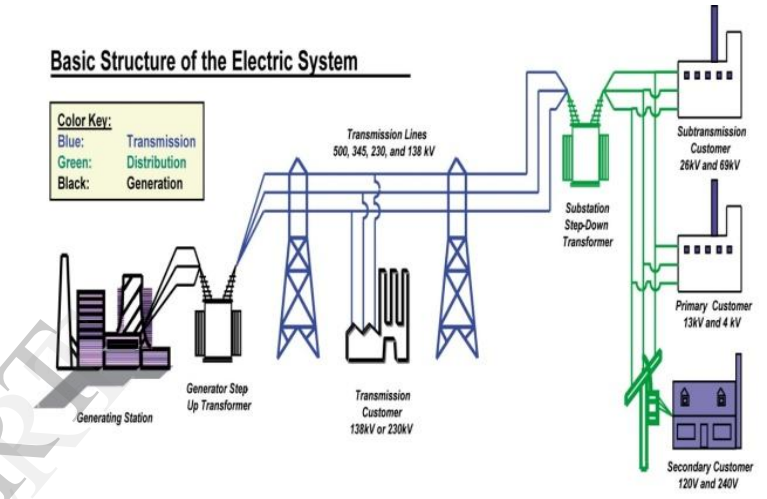

Figure 1: Basic structure of Electrical System

\subsection{Reactive Power}

\subsubsection{About}

Explanation for reactive power says that in an alternating current system, when the voltage and current go up and down at the same time, only real power is transmitted and when there is a time shift between voltage and current both active and reactive power are transmitted. But, when the average in time is calculated, the average active power exists causing a net flow of energy from one point to another, where as average reactive power is zero, irrespective of the network or state of the system. In the case of reactive power, the amount of energy flowing in one direction is equal to the amount of energy flowing in the opposite direction (or different parts -capacitors, inductors, etc- of a network, exchange the reactive power). That means reactive power is neither produced nor consumed. 


\subsubsection{Power Triangle}

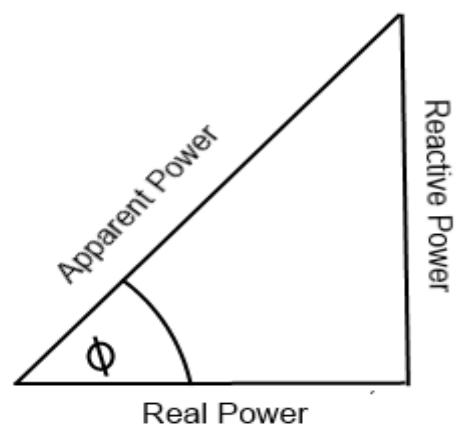

Figure 2: Power factor triangle

Energy stored in capacitive or inductive elements of the network give rise to reactive power flow. Reactive power flow strongly influences the voltage levels across the network. Voltage levels and reactive power flow must be carefully controlled to allow a power system to be operated within acceptable limits

\subsubsection{Need of Reactive Power} 1

Active power is the energy supplied to run a motor, heat a home, or illuminate an electric light bulb. Reactive power provides the important function of regulating voltage. If voltage on the system is not high enough, active power cannot be supplied. Reactive power is used to provide the voltage levels necessary for active power to do useful work.

Reactive power is essential to move active power through the transmission and distribution system to the customer .Reactive power is required to maintain the voltage to deliver active power (watts) through transmission lines. Motor loads and other loads require reactive power to convert the flow of electrons into useful work. When there is not enough reactive power, the voltage sags down and it is not possible to push the power demanded by loads through the lines.

\section{Methods of controlling reactive power}

The reactive power in the line can be controlled by following methods

$\begin{array}{ll}- & \text { Conventional method } \\ \text { - } & \text { Automatic Generation Control } \\ \text { - } & \text { Transformer Tap Changer Control } \\ \text { - } & \text { Phase shifting Transformer } \\ \text { FACTS devices }\end{array}$

\subsection{Conventional method}

In a conventional ac power system, however, most of the Controllability exists at generating station. For example, Generators called spinning reserves maintain an instantaneous Balance between power demand and power supply. These generators, In FACT, are purposely operated at reduced power. Also, to regulate the system frequency and for maintaining the system at the rated voltage control are exercised on selected generator.

\subsection{Automatic Generation Control}

The megawatt (MW) output of a generator is regulated by Controlling the driving torque $T_{m}$ provided by a prime mover turbine. In a conventional electromechanical system, it could be steam or hydraulic turbine. The needed change in the turbine -output torque is achieved by controlling the steam/water Input into the turbine. Therefore, in situation where the output exceed or falls below the input, a speed-governing system senses the deviation in the generator speed because of the load generation mismatch, adjust the mechanical driving torque to restore the power balance; and return the operating speed to its rated value. The speed-governor output is invariably taken through several stages of mechanical amplification for controlling the inlet valve/gate of the driving turbine. Figure shows the basic speed governing system of a generator supplying an isolating load. The operation of this basic feedback control system is enhanced by adding further control inputs to help control the frequency of a large interconnection. In that role, the control system becomes an automatic generation control (AGC) with supplementary signals.

To avoid competing control action, in a multi generator unit station each speed governor system is provided with droop $(\mathrm{R})$ characteristics through a proportional feedback unit(R, Hz/MW). Figure 2 shows an AGC on the principal generating unit with supplementary control. In contrast the second, third and remaining generating units in a multiunit station operate with their basic AGCs. IN a complex interconnected system, the supplementary control signals may be determine by a loaddispatch centre.

\subsection{Excitation Control}

The basic function of an exciter is to provide a dc source for field Excitation of a synchronous generator. A control on exciter voltage Results in controlling the field current, which, in turn, control the Generated voltage .when a synchronous 
generator is connected To a large system where the operating frequency and the terminal Voltage are largely un affected by a generator, its excitation control causes its reactively power output to change. In older power plants a dc generator also called an exciter, was Mounted on the main generator shaft. A control of the field excitation of the dc generator provided a controlled excitation source for the main Generator. In contrast, modern station employs either a brushless Exciter or a static exciter. An excitation control system employs a voltage controller to control the excitation voltage. This operation is typically recognized as an Automatic voltage regulator. However, because an excitation control operates quickly, several stabilizing and protective signals are invariably added to the basic voltage regulator. A power system Stabilizer is implemented by adding auxiliary damping signals derived from the shaft speed or the terminal frequency of power an effective and frequently used technique for enhancing small signal of the connected System.

\subsection{Transformer Tap Changer Control}

Next to the generating units, transformer constitutes the second Family of major power transmission system apparatus. In Addition to increasing and decreasing nominal voltages, many Transformers are equipped with tap-changer to realize a Limited range of voltage control. These tap changers usually available: off load tap changers, which are equipped with Current commutation capacity and are operated under load. Tap changer may provide one of the two transformer winding As well as on autotransformers. Because tap-changing transformer vary voltages and, therefore, the reactive power flow, these transformers may be Used as reactive power control devices. On-load tap-changing Transformer is usually employed to correct voltage profiles on hourly or daily basis to accommodate loads variation. Their Speed of operation is generally slow and frequently operations Result in electrical and mechanical wear and tear.

\subsection{Phase Shifting Transformer}

A special form of a 3-phase -regulating transformer is realized By combining a transformer that is connected in series with a Line to a voltage transformer equipped with a tap changer. The windings of a voltage transformers are so connected that $\mathrm{On}$ its secondary side, phasequadrature voltages are generated And fed into secondary windings of the series transformer. Thus the addition of small, phase quadrature voltage components to the phase voltage of the line creates phase shifted output Voltages without any appreciable change in magnitude. A phase shifting transformer is therefore able to introduce a phase shifting a line. Figure shows such an arrangement together with a Phasor Diagram. The Phasor diagram shows the phase shift realized without an appreciable change in magnitude by the injection of phase Quadrature voltage components in a 3-phase system. When a Shift transformer employs an onload tap changer controllable Phase-shift is achieved. The interesting aspect of such phase Shifter is that despite their low MVA capacity, by controlling, the phase shift they exercise a significant real power control.

\subsection{FACTS devices}

FACT controller is power electronics based device and other static equipment for control of one or more parameters of AC transmission line.

\section{Advantages of FACT devices}

1. FACT devices reduce power losses and improve voltage profile.

2. They increase the loading capability of lines.

3 . The amount of reactive power is controlled. When reactive power increases in line, it is absorbed by FACT devices while when the reactive power decreases, the FACT devices provide reactive power.

4. So by controlling reactive power, more active power can be transferred and so voltage can be controlled.

5. The older generators can be efficiently used such as for peak load only. The base load can be provided by newer and efficient generators,

\subsubsection{Fixed capacitor thyristor controlled reactor (FC-TCR)}

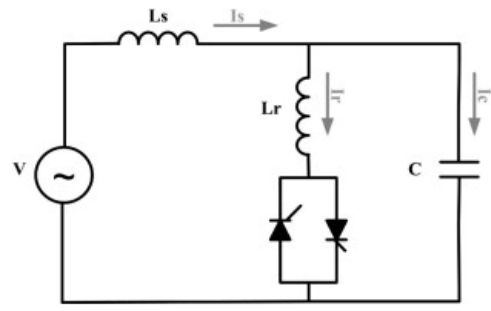

Figure 3: Fixed capacitor thyristor controlled reactor

Static VAR compensated FACTS device are the most important device and have been used for 
a number of years to improve voltage and power flow through the transmission line by resolving dynamic voltage problems. SVC is shunt connected static generator/absorber. Utilities of SVC controller in transmission line are many:

(A) Provides high performance in steady-state and transient voltage stability control,

(B) Dampen power swing,

(C) Reduce system loss,

(D) Control real and reactive power flow.

Simple FC-TCR type SVC configuration is shown in figure 1. In FC-TCR, a capacitor is placed in parallel with a thyristor controlled reactor. Is, Ir and Ic are system current, reactor current and capacitor current respectively which flows through the FC-TCR circuit. Fixed capacitor- Thyristor controlled reactor (FC-TCR) can provide continuous lagging and leading VARS to the system [5]. Circulating current through the reactor (Ir) is controlled by controlling the firing angle of back-back thyristor valves connected in series with the reactor. Leading var to the system is supplied by capacitor. For supplying lagging vars to the system, TCR is generally rated larger than the capacitor.

\subsubsection{Static synchronous compensator (STATCOM)}

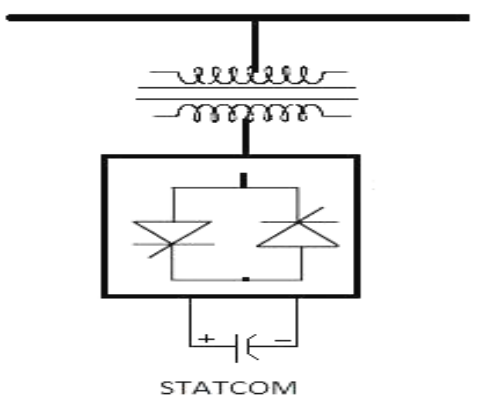

Figure 4: Static synchronous compensator

The static synchronous compensator (STATCOM) is another shunt connected GTO based FACTS device. STATCOM is a static synchronous generator operated as a static VAR compensator which can inject lagging or leading var into the system. STATCOM have several advantages. It has no rotating parts, very fast in response, requires less space as bulky passive components are eliminated, inherently modular and reloadable, less maintenance and no problem as loss of synchronism .Simple diagram of STATCOM is shown in figure. The dc source voltage is converted into ac voltage by the voltage source converter using GTO and ac voltage is inserted into the line through the transformer. In heavy loaded condition if. Output of VSC is more than the line voltage, converter supplies lagging VARs to the transmission line. During low load condition if line voltage is more than then converter absorbs lagging VAR from the system. If $\mathrm{o} / \mathrm{p}$ voltage of converter is equal to line voltage, then the STATCOM is in floating condition and this shunt device does not supply or absorb reactive power to the system or from the system.

\subsubsection{Thyristor controlled series capacitor (TCSC)}

Thyristor controlled series capacitor (TCSC) is very important series compensator like SSSC. Especially in this FACTS (Flexible alternating transmission system) device, thyristor with gate turn-off capability is not required. Figure 3 shows schematic diagram of a TCSC controller. In TCSC, capacitor is inserted directly into the transmission line and TCR are mounted in parallel with the capacitor. As the capacitor is inserted in series with the line, there is no need of using high voltage transformer and thus it gives better economy. Firing angle of back to back thyristors are controlled to control the reactor. At $180^{\circ}$ firing angle TCR, is non- conducting and at $90^{\circ}$ firing angle TCR is in full conduction.

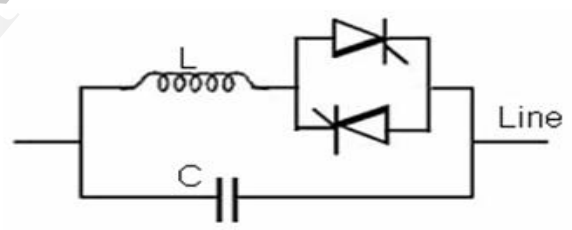

Figure 5: Thyristor controlled Series Capacitor

\subsubsection{Static synchronous series compensator (SSSC)}

In present days, SSSC is one of the most important FACTS controller used for series compensation of power. In series compensation the capacitor which is connected in series compensates the inductive reactance of the transmission line. SSSC output voltage $\left(\mathrm{V}_{\mathrm{C}}\right)$ is in quadrature with the line current (I). The voltage across series capacitor is $-\mathrm{j} \mathrm{X}_{\mathrm{C}} \mathrm{I}$ (where $\mathrm{Xc}$ is the capacitive reactance of the series capacitor) and voltage drop across line inductance $\left(\mathrm{X}_{\mathrm{L}}\right)$ is $+\mathrm{j} \mathrm{X}_{\mathrm{L}} \mathrm{I}$ cancel each other thus reducing the effect of line inductance. Due to this, power transfer capability is increased.The symbolic representation of SSSC using voltage 


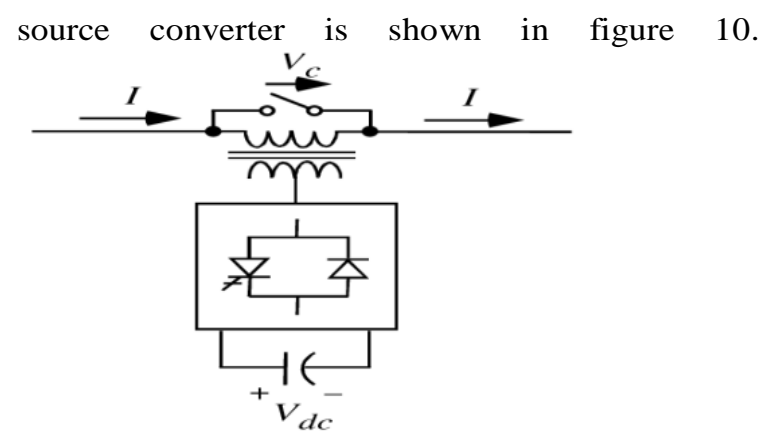

Figure 6: Static synchronous series compensator

Supply voltage from a dc source is converted into ac voltage using VSC (voltage source converter). Quadrature voltage is injected into the line through a coupling transformer. This injected voltage $(\mathrm{Vc})$ lags the line current (I) by $90^{\circ}$ and series compensation is done. SSSC control flow of real and reactive power through the system.

\subsubsection{Unified power flow controller (UPFC)}

Figure. 11 shows a schematic diagram of UPFC. Full form of UPFC is Unified power flow controller. The word unified signifies all parameters (e.g. - voltage, phase angle, impedance, real and reactive power and power FACTOR) which effect power flow in the system can be controlled. UPFC is the most modernised device among all the FACTS devices which can be used to enhance steady-state stability, dynamic stability, and real and reactive power flow and so on. UPFC consists of two converters. One converter (SSSC) is connected in series with the transmission line and other converter (STATCOM) is connected in parallel with the transmission line. The two converters are coupled through a common dc link which provides bidirectional flow of real power between series o/p SSSC and shunt output STATCOM respectively. For balancing of power between series and shunt controller it is necessary to maintain constant voltage across the dc link. Series branch (SSSC) of the UPFC injects variable magnitude voltage and phase angle. This improves power flow capability and transient stability .Shunt branch (STATCOM) maintains the balance between the real power absorption from and injection into the system.

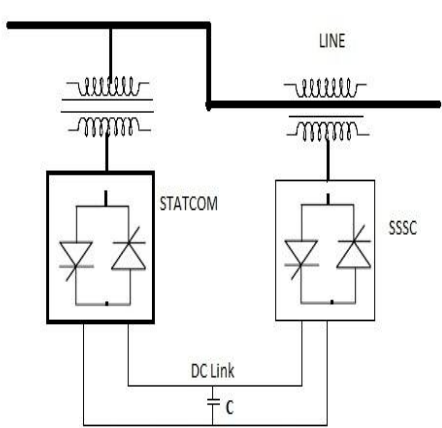

Figure 7: Unified power flow controller

\subsection{Mathematical modelling of long Trans line}

We know that for loss less line voltage and current is given by,

$\overline{V(x)}=\overline{V S} \cos \beta x-\mathrm{j}$ Zo $\overline{I s} \sin \beta x$,

$\overline{I(x)}=\overline{I S} \cos \beta x-\mathrm{j} \overline{V s} / \mathrm{Zo} \sin \beta x$

These equations are used to calculate voltage and current anywhere on line, at a distance of $\mathrm{x}$ from sending end, in terms of sending end voltage and current and the line parameters.

If we put,

$\mathrm{Zo}=\sqrt{l / c} \Omega$

$\beta=\omega \sqrt{l c} \mathrm{rad} / \mathrm{km}$

$\beta a=\omega \sqrt{l c a} \mathrm{Rad} / \mathrm{km}$

Where $l$ the line inductances in $(\mathrm{H} / \mathrm{km})$ is, $c$ is the line shunt capacitance in $(\mathrm{F} / \mathrm{km})$ and $1 / \sqrt{ } l c$ is the propogation velocity of electromagnetic effects on the transmission lines.

From eq. we get,

$\overline{I s}=\frac{\overline{V s} \cos \beta a-\overline{V r}}{j Z 0 \sin \beta a}$

Power at the sending end is given by

$S s=P s+j Q s=\overline{V s I s} *$

Where,

$P s=-P r=\frac{V^{2}}{Z \sin \beta a} \sin \delta$

And,

$Q s=Q r=V^{2} \cos \beta a-\frac{V^{2} \cos \delta}{Z \operatorname{losin} \beta a}$

\subsection{Case Study}

Now for $735-\mathrm{kv}$ lossless transmission line with $l=0.932 \mathrm{mH} / \mathrm{km}, c=12.2 \mathrm{nF} / \mathrm{km}$, and length of line is $800 \mathrm{~km}$,

$Z o=\sqrt{\frac{l}{c}}=\sqrt{\frac{0.932}{12.2}} 10^{3}=276.4 \Omega$ 
Therefore, the SIL is

$$
P o=\frac{V^{2} \text { nom }}{Z o}=\frac{\left(735 \times 10^{3}\right)^{2}}{276.4}=1954.5 \mathrm{MW}
$$

For this line to operate as a symmetrical line, that is,

$V s=V r=735 \mathrm{Kv}$, we have

$P s=\frac{V s}{Z o \sin \beta a} \sin \delta$

$$
=\frac{735^{2}}{276.4 \sin [(\omega \sqrt{l c}) 800]} \sin \delta
$$

$P_{s}=2298.5 \sin \delta M W$

$P_{s}=1.176$ Po $\sin \delta M W$

The various values of Active and Reactive Power of the load for different values of load angle $\delta$ are as follows

\section{MATLAB Simulation in simulink environment}

\subsection{Uncompensated Transmission Line}

To illustrate a number of important considerations, we choose a $735 \mathrm{KV}$ symmetrical lossless transmission line with inductance $1=0.932 \mathrm{mH} / \mathrm{km}$, capacitance $\mathrm{c}=12.2 \mathrm{nF} / \mathrm{km}$ and line length of 800 $\mathrm{km}$. The source resistance is negligible resistance. The simulation of line is done in MATLAB SIMULINK.

In order to simulate the long line in the MATLAB we have taken 40 pi sections

Per $400 \mathrm{~km}$ i.e. 1 pi section every $10 \mathrm{~km}$.

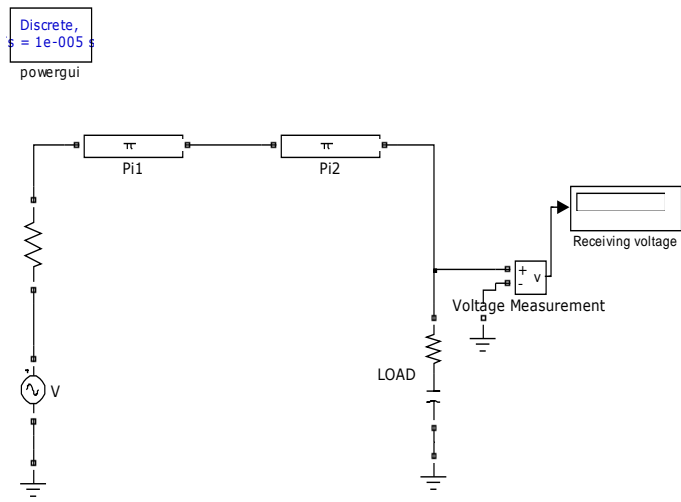

Figure 8: Uncompensated Transmission Line

The voltage at the receiving end is of our concern. The voltage is measured by a voltage measurement device and displayed in the dialog box.

For value of load angle $\delta=30$, the load is light load. Hence the voltage at receiving side is more than sending side.
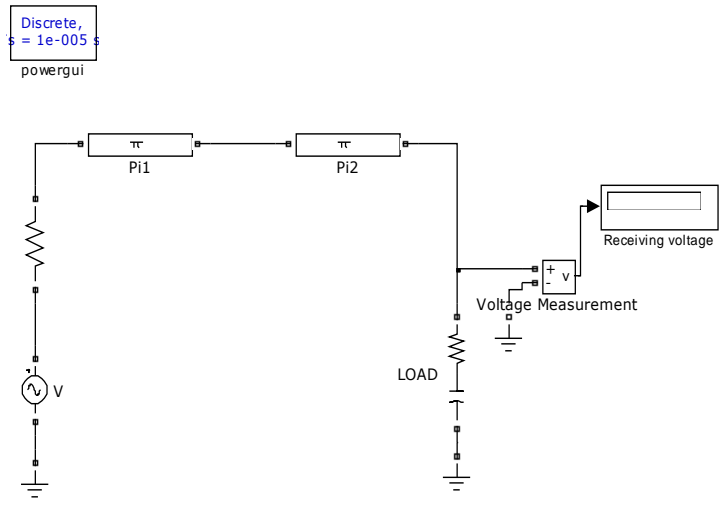

Figure 9: Uncompensated Transmission Line at 30 degree

For load angle $\delta=60$, the load is heavy load. So the voltage at load side is less than sending side.

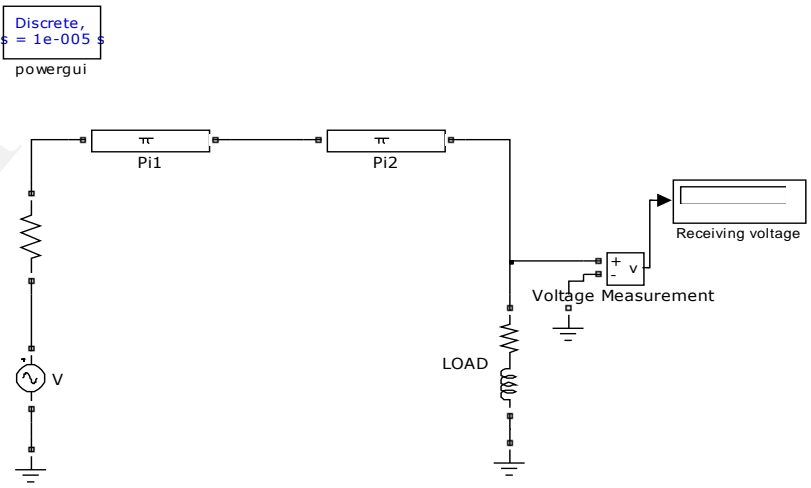

Figure 10: Uncompensated Transmission Line at 60 degree

For load angle $\delta=S I L\left(48.56_{-}^{\circ}\right)$, the load voltage is equal to receiving voltage without any compensation

\subsection{Compensated transmission line}

There was no compensation provided in the previous uncompensated line. So the receiving voltage was not equal to sending voltage. By providing compensation by FACT devices, we can get equal voltage profile all over the line.

We will compensate the transmission line with 5 FACTs devices-

FCTCR-Fixed Capacitor Thyristor Controlled Reactor - Shunt Controller STATCOM-Static Compensator - Shunt Controller SSSC-Static Synchronous Series Capacitor - Series Controller 
TCSC-Thyristor Controlled Series Capacitor Series Controller

UPFC-Unified Power Flow Controller - ShuntSeries Controller

\subsection{FCTCR Compensated line}

The subsystem circuit of FCTCR is as follows
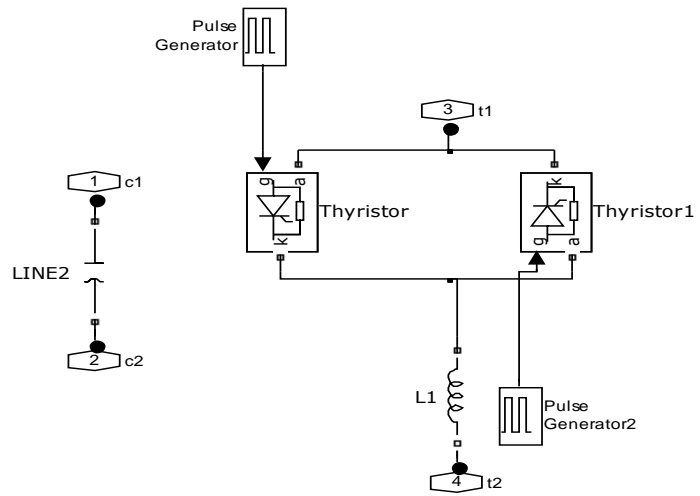

\section{Figure 11: FCTCR circuit}

The value of inductance is assumed to be $1 \mathrm{mH}$ for all the FACT devices. The FCTCR is shunt connected to the long transmission line as shown below.
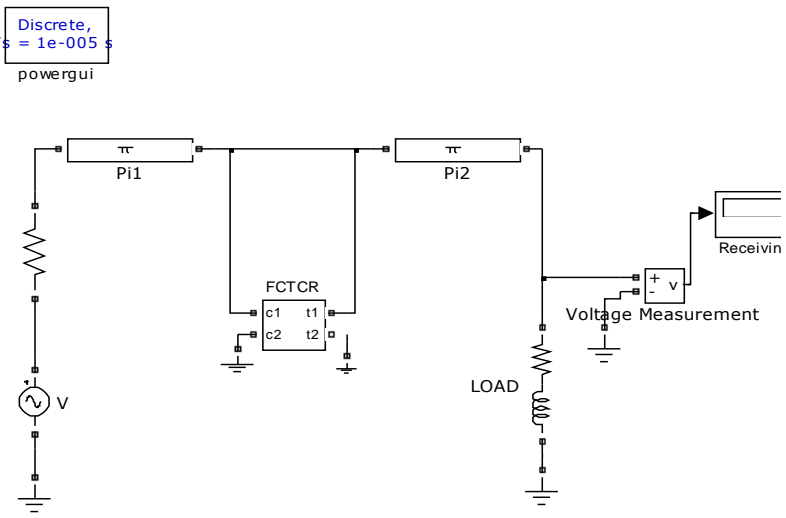

Figure 12: FCTCR compensated line

\subsection{STATCOM compensated line}

The subsystem circuit of STATCOM is as follows

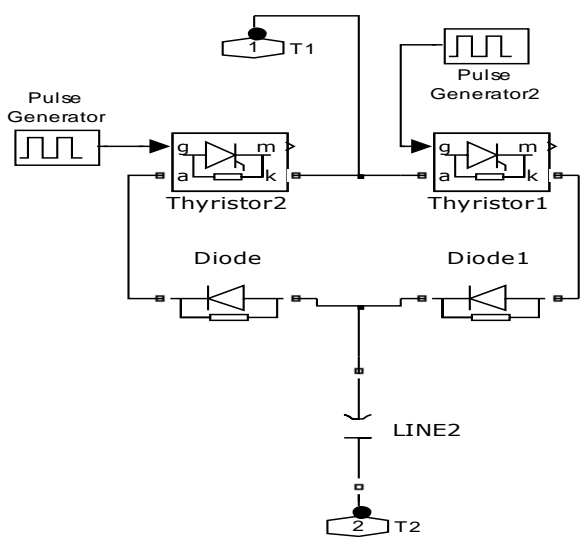

Figure 13: STATCOM circuit

Just as FCTCR, the STATCOM is shunt connected.

\subsection{TCSC compensated line}

The subsystem circuit of TCSC is as follows

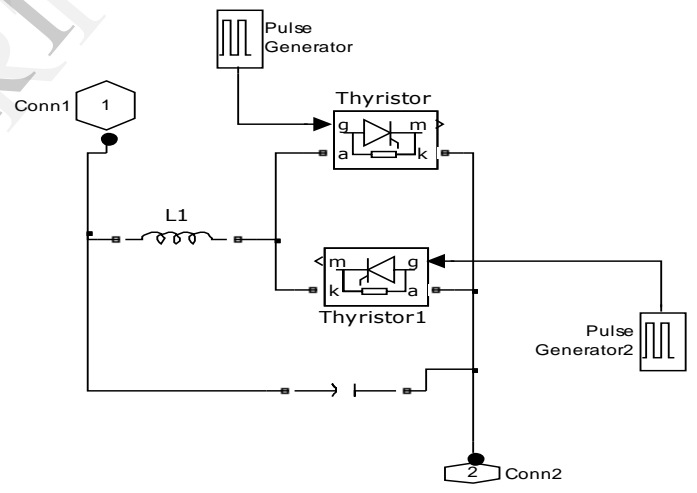

Figure 34: TCSC circuit

\subsection{SSSC compensated line}

The subsystem circuit of SSSC is as follows 


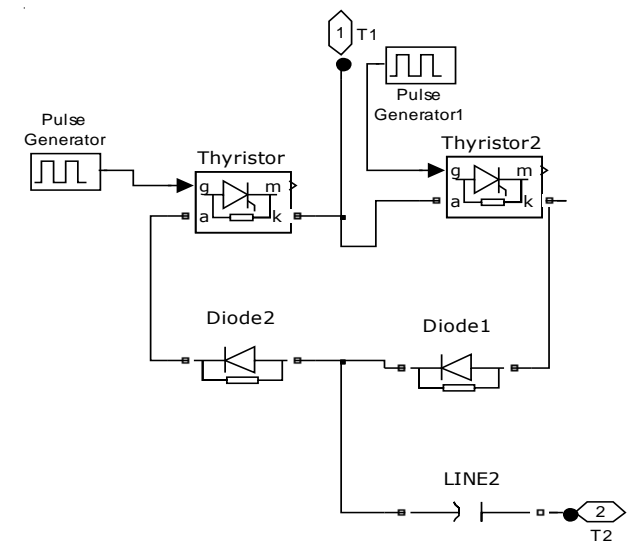

Figure 45: SSSC circuit

The SSSC is series connected to line as shown below:

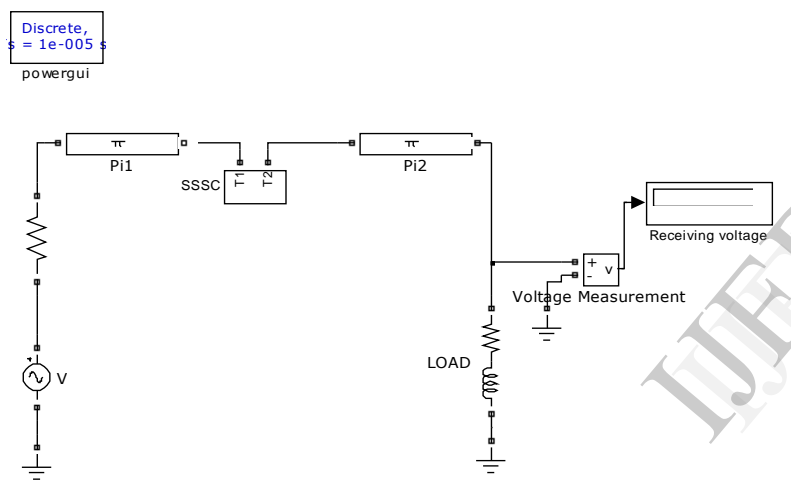

Figure 16: SSSC compensated line

\subsection{UPFC compensated line}

The subsystem circuit of UPFC is as follows:

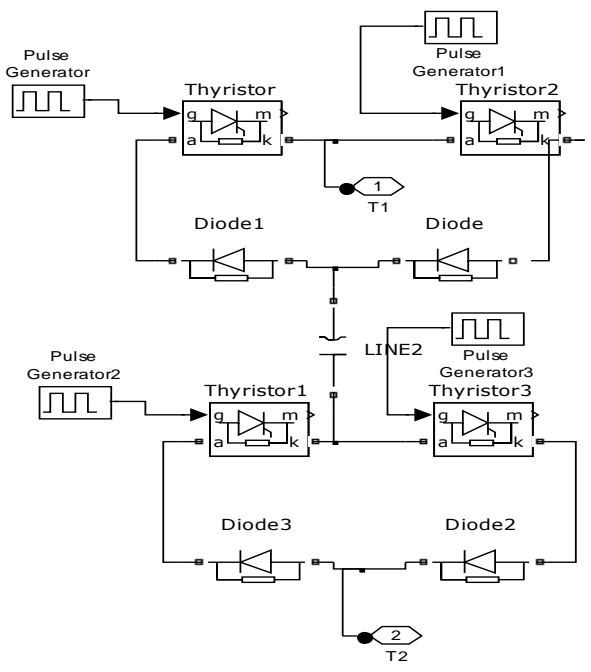

Figure 17: UPFC circuit

\section{Results}

(a). Receiving end voltage for uncompensated line, for different value of load angle $\delta\left(30^{\circ}, 48.56^{\circ}\right.$ and $\left.60^{\circ}\right)$ are as follows :

\begin{tabular}{|l|l|l|l|}
\hline $\begin{array}{l}\text { Type of } \\
\text { load }\end{array}$ & $\delta$ & $\begin{array}{l}\text { Sending } \\
\text { Voltage }\end{array}$ & $\begin{array}{l}\text { Receiving } \\
\text { Voltage }\end{array}$ \\
\hline $\begin{array}{l}\text { Lightly } \\
\text { Loaded }\end{array}$ & $30^{\circ}$ & $735 \mathrm{KV}$ & $\begin{array}{l}1083.91 \\
\mathrm{KV}\end{array}$ \\
\hline SIL & $48.56^{\circ}$ & $735 \mathrm{KV}$ & $735 \mathrm{KV}$ \\
\hline $\begin{array}{l}\text { Heavily } \\
\text { Loaded }\end{array}$ & $60^{\circ}$ & $735 \mathrm{KV}$ & $\begin{array}{l}614.83 \\
\mathrm{KV}\end{array}$ \\
\hline
\end{tabular}

When the load angle $\delta=30^{\circ}$, there is excess of reactive power in the line. So the receiving side voltage is more than sending side voltage. This effect is called Ferranti effect. $\left(V_{r}>V_{s}\right)$

When the load angle $\delta=60^{\circ}$, there is shortage of reactive power in the power system. So the receiving side voltage is less than sending side voltage. $\left(V_{r}<V_{s}\right)$

When the load angle $\delta$ is equal to $48.56_{-}^{\circ}$ (SIL), the reactive power generated is equal to reactive power consumed. So the receiving side voltage is equal to sending side voltage. $\left(V_{r}=V_{s}\right)$ 
(b). The value of capacitor in $\mu F$ for different FACT devices to maintain voltage profile flat in a compensated line i.e. $V_{s}=V_{r}$ are as follows:

\begin{tabular}{|c|c|c|c|c|c|}
\hline \multirow{2}{*}{$\boldsymbol{F}$} & $\begin{array}{c}\text { FCTC } \\
\text { R }\end{array}$ & $\begin{array}{c}\text { STATC } \\
\text { OM }\end{array}$ & SSSC & TCSC & UPFC \\
\hline \multirow{2}{*}{$30^{\circ}$} & 84.1775 & 46.3935 & 12.7706 & 84.1775 & 46.3755 \\
& $\mu F$ & $\mu F$ & $\mu F$ & $\mu F$ & $\mu F$ \\
\hline \multirow{2}{*}{$60^{\circ}$} & $\begin{array}{c}97.0445 \\
\mu F\end{array}$ & 5.3412 & 12.7885 & 97.0351 & 5.3402 \\
& $\mu F$ & $\mu F$ & $\mu F$ & $\mu F$ \\
\hline
\end{tabular}

The SSSC has lowest and constant value of capacitance among the different FACT devices.

\section{Conclusion}

The value of capacitance required for compensation for different fact devices is seen. The value of capacitance is usually fixed and so we need a capacitance that can act for both the light load and heavy load.

We can see that the SSSC has lowest value of capacitance and it is almost constant for every load condition.

Hence, it can be concluded that SSSC provides most economical performance when voltage stability of the power system is concerned as compared to other FACTS devices.

\section{References}

[1] R.M.Mathur / R.K.Verma, "Thyristor-Based FACTS Controllers for Electrical Transmission Systems", John Wiley \& Sons, Inc., 2002

[2] CIGRE, "FACTS Overview", IEEE Power Engineering Society, 95 TP 108, April 1995.

[3] K.R.Padiyar,'FACTS controllers in power transmission and distribution", New Age Publication

[4] N. G Hingorani \& Laszlo Gyugyi, "Understanding FACTS: concepts and technology of flexible AC transmission System", IEEE Press, New York (2000).

[5] Tyll, H.K. "Application of SVCs to Satisfy Reactive Power Needs of Power Systems",IEEE Conference 2006

[5] K. R. Padiyar, "FACTS controllers in power transmission and distribution, "New Age Int. Publisher, 2007.

[6] Abhijit Chakrabarti \& Sunita Halder, "Power System Analysis Operation and Control". Prentice Hall of India Pvt. Limited, New Delhi, 2006.

[7] Dr.B.R.Gupta \& Er.Vandana Singhal,
"Power System Operation and Control", S. Chand Publications.

[8] D. Murali, Dr. M. Rajaram\& N. Reka, "Comparison of FACTS Devices for Power System Stability Enhancement", International Journal of Computer Applications", Volume8- No.4, October 2010.

[9] Bhavin. M. Patel, "Enhancement of Steady State voltage Stability Using SVC and TCSC”, National Conference on Recent Trends in Engineering \& Technology, 13-14May2011. [10] Rahul Somalwar, Manish Khemariya, " $A$ Review of Enhancement of Transient Stability by FACTS Devices", International Journal of Emerging Technologies in Sciences and Engineering, Vol.5, No.3, March 2012. 